\title{
Chemical Solution Deposition of functional ceramic coatings using ink-jet printing
}

\author{
K. De Keukeleere, G. Pollefeyt, J. Feys, J. De Roo, H. Rijckaert, \\ P. Lommens and I. Van Driessche
}

Krijgslaan 281 (S3), 9000 Ghent, Belgium

\begin{abstract}
This paper discusses the development of environmentallyfriendly precursor inks suited for ink-jet printing of functional ceramic coatings. We synthesized superconducting materials, $\mathrm{SrTiO}_{3}$ thin films for coated conductor applications and transparent $\mathrm{TiO}_{2}$ photocatalytic coatings. Here, we discuss all aspects of ink formulation, including the stabilization of metal ions, nanoparticle inks or combination of both. This demands the investigation and determination of the inks rheological parameters. Ceramic nanoparticles are often incorporated in our inks to decrease thermal processing temperatures (e.g. $\mathrm{TiO}_{2}$ or YSZ coatings...) or enhance the properties of the functional ceramic coating (e.g. pinning centres in superconducting coatings). These ceramic nanoparticles $\left(\mathrm{ZrO}_{2}\right.$, $\left.\mathrm{HfO}_{2}, \mathrm{TiO}_{2} \ldots\right)$ are synthesized through methods based on microwave heating from aqueous and/or organic solutions. With that, we aim at developing smart and environmentally friendly processes that require lower energy input.
\end{abstract}

\section{INTRODUCTION}

Functional ceramic coatings are required for innovations in communication, electronics, energy technology and catalysis. In our research, we focus on chemical solution deposition (CSD) techniques to deposit ceramic precursor inks, which will be processed into a functional ceramic coating.[1-6]

We use different precursor inks, depending on the application: complexated metal ions inks, an ink containing solely ceramic nanoparticles (NPs) or a combination of complexated metal ions and ceramic NPs. The use of NPs offer interesting advantages like lower final processing temperatures for inks solely consisting of NPs (e.g. $\mathrm{TiO}_{2}$ coatings) or enhanced properties of the final ceramic layer for metal ions-NPs inks (e.g. nanoparticles in superconducting materials). So, a proper knowledge on ink stability of all types of inks is necessary. Coordination chemistry of the metal ions with complexing agents is studied through stability constants, potentiometric titrations and EPR analysis[7], while NP stability is analyzed through dynamic light scattering (DLS) and transmission electron microscopy (TEM) measurements.

In this paper, alternative processing methods are used to synthesize ceramic NPs, based on microwave heating from aqueous and/or organic solutions. Microwaves directly heat the precursor solution, making fast temperature build-up and cool-down possible. This leads to a fast supersaturation, fast crystallization and shorter reaction times in comparison to conventional heating.[8-13] The as-synthesized nanoparticles can be stabilized in either polar or non-polar 
solvents, dependent on the processing requirements.[14] These nanoparticles containing inks can be deposited using ink-jet printing at ambient pressure.

Ink-jet printing has been used for many years in depositing text or patterns on textile or paper.[15] Only recently there has been a growing interest in using the deposition technique for functional ceramic coatings and patterns.[1, 3, 5, 16-19] The biggest advantage of ink-jet printing as a one-step process is its low investment cost, scalability, the more efficient use of materials and the high control of the thickness of the coating.[15] The fluid properties of newly developed inks are analyzed to determine the printability and is expressed with dimensionless constants, like the Reynolds and Weber numbers. [1, 5, 15]

We use the knowledge on ink formulation and ink-jet printing for the formation of $\mathrm{SrTiO}_{3}$ thin films for coated conductor applications, high-temperature superconducting coated conductors and transparent $\mathrm{TiO}_{2}$ photocatalytic coatings which will be discussed below.[1, 3, 5, 16-19] However, we have also developed YSZ coatings for solid oxide fuel cells and thermal barrier coatings, or LMSO magneto-resistive systems to obtain functional magneto-resistive patterns, which can be found elsewhere.[20, 21]

\section{INK PREPERATION}

\section{Solution ink formulation}

In our research, we aim at the formulation of environmentally-friendly precursor inks. These are in general water-based, containing metal ions stabilized by carefully selected complexing agents. This avoids hydrolysis and uncontrolled precipitation reactions, limiting the shelf life of the precursors. The stability of the inks can be predicted by studying the complexation behavior of the different metal ions with complexing agents as a function of $\mathrm{pH}$ via speciation distribution diagrams, using specific software (Hyss2006) that can calculate speciation distribution diagrams based on stability constants obtained from literature or experimentally through potentiometric titrations.[22] An example of a speciation distribution diagram for an aqueous $\mathrm{YBa}_{2} \mathrm{Cu}_{3} \mathrm{O}_{7-x}$ (YBCO) precursor ink can be found in Fig. 1. The ink contains triethanolamine (TEA) and nitrilotriacetic acid (NTA) as complexing agents to stabilize the yttrium, barium and copper ions in solution. Detailed information on this subject can be found in [1] From the generated data, one can see that the $\mathrm{pH}$ of the precursor should be below $\mathrm{pH} 10$, because any dissolved $\mathrm{Y}(\mathrm{OH})_{3}$ will precipitate . However, the $\mathrm{pH}$ range should be limited to 6-10, because the presence of free metal ions need to be avoided during gel formation of a film, which can otherwise cause precipitation. In practice, the useful $\mathrm{pH}$ range is even more limited to a range between 6 and 8 , to prevent corrosion of nozzle parts.

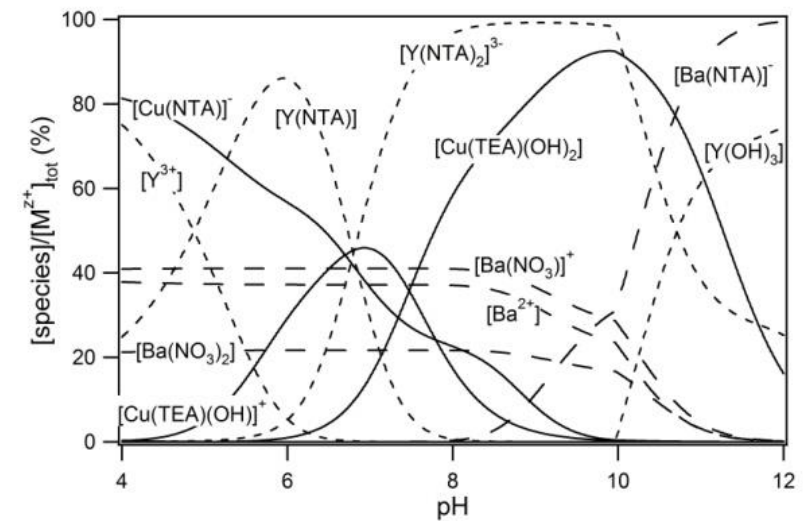

Fig. 1 Speciation diagram for an aqueous YBCO solution, containing $0.474 \mathrm{~mol} / \mathrm{L} \mathrm{Cu}\left(\mathrm{NO}_{3}\right)_{2}, 0.158$ $\mathrm{mol} / \mathrm{L} \mathrm{Y}_{2}\left(\mathrm{CO}_{3}\right)_{3}, 0.313 \mathrm{~mol} / \mathrm{L} \mathrm{Ba}(\mathrm{OH})_{2}, 0.426 \mathrm{~mol} / \mathrm{L} \mathrm{NTA}$ and $1.586 \mathrm{~mol} / \mathrm{L}$ TEA, showing the relative

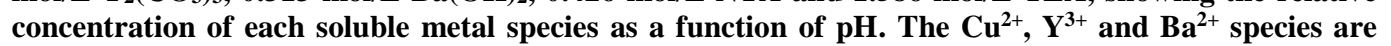
respectively denoted as the solid, dotted and dashed line. 
Once a clear, stable solution is obtained, it is important to confirm that also upon evaporation of the solvent, a clear gel (being hard or sticky) depending on the complexing agent and $\mathrm{pH}$ conditions is obtained (Fig. 2). With this respect, spectroscopy tools such as Raman, IR and EPR prove very useful in confirming the formation of different types of coordination bonds between stabilizers and metal ions. This is shown in Fig. 2 for aqueous $\mathrm{SrTiO}_{3}$ solutions. By comparing the Raman spectra of single metal solutions and their metal-free matrices, characteristic vibrations of the formed complexes can be determined. These vibrations can then be studied in the precursor inks in order to determine the metal complexes present in the solution. [4]
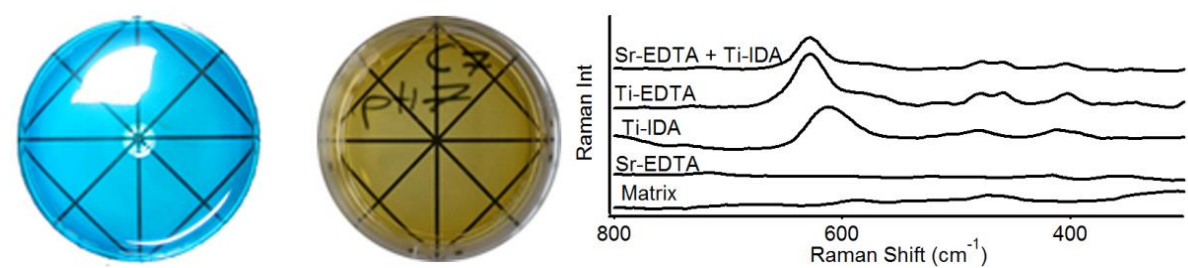

Fig. 2 From left to right: aqueous YBCO ink, aqueous STO ink, Raman spectrum of chelated $\mathrm{Ti}^{4+}$ solution with both imino-diacetic acid and EDTA.

\section{INK-JET DEPOSITION}

Two different types of so-called drop-on-demand (DOD) printer systems are used in our research group: the piezo-electric and the electromagnetic actuated printing system. The differences between these two systems are summarized in Table 1.

Table 1. Drop-on-demand (DOD) piezo-electric versus electromagnetic actuated printing systems.

\begin{tabular}{|l|l|l|}
\hline Printer system & Electromagnetic & Piezo-electric \\
\hline Droplet volume & $4 \mathrm{~nL}-1 \mu \mathrm{L}$ & $1-100 \mathrm{pL}$ \\
\hline Operating pressure & $0.05-2$ bar positive pressure & Small negative pressure \\
\hline Viscosity range & Limited $(10-15 \mathrm{mPa} . \mathrm{s})$ & $\eta_{\max }=40 \mathrm{mPa} . \mathrm{s} ; \eta_{\text {optimim }}=6-14 \mathrm{mPa} . \mathrm{s}$ \\
\hline Resolution & Low & High \\
\hline Diameter orifice & $\begin{array}{l}\text { Domino: } 90 \mu \mathrm{m} \\
\text { Fitz Gyger: } 100 \mu \mathrm{m}\end{array}$ & $\begin{array}{l}\text { Dimatix Materials Printer: } 9-22 \mu \mathrm{m} \\
\text { Microfab: } 15-30-60 \mu \mathrm{m}\end{array}$ \\
\hline
\end{tabular}

The generation of droplets in the printer systems is complex and is dependent on the fluid properties. These fluid properties can be predicted by the Ohnesorge (Oh) number, a dimensionless constant.

$$
\mathrm{Oh}=\eta / \sqrt{\sigma \rho \mathrm{r}}
$$

With $\sigma, \rho, \eta$ and $\mathrm{r}$ the ink surface tension $\left(\mathrm{J} \mathrm{m}^{-2}\right)$, density $\left(\mathrm{kg} \mathrm{m}^{-3}\right)$, viscosity $(\mathrm{Pa} \mathrm{s})$ and $\mathrm{r}$ the diameter of the nozzle's orifice $(\mathrm{m})$ respectively. The inverse Ohnesorge number $\left(\mathrm{Oh}^{-1}\right)$ is independent on the droplet velocity and provides information on jetting properties. Good jetting properties are obtained when $1<\mathrm{Oh}^{-1}<10$.[15] At lower values, drop ejection will not occur due to high viscous forces. While at higher values, satellite drop formation is more likely to occur. Nevertheless, systems with inverse Ohnesorge numbers higher than 10 have been shown to be printable by multiple research groups.[3, 23] Table 2 shows an example of fluid properties of aqueous YBCO and STO inks. Given the different nozzle diameters different $\mathrm{Oh}^{-1}$ are obtained depending on the used printer system (Table 3). 
Table 2. Fluid properties of aqueous STO and YBCO inks.

\begin{tabular}{|c|c|c|c|}
\hline Precursor Ink & Surface tension $\boldsymbol{\sigma}\left(\mathbf{J ~ m}^{-2}\right)$ & Density $\boldsymbol{\rho}\left(\mathbf{k g ~ m}^{\mathbf{3}}\right)$ & Viscosity $\boldsymbol{\eta}(\mathbf{P a} \mathbf{~ s})$ \\
\hline STO & $5.91 \times 10^{-2}$ & 1165 & $2.7 \times 10^{-3}$ \\
\hline YBCO & $6.79 \times 10^{-2}$ & 1233 & $6.8 \times 10^{-3}$ \\
\hline
\end{tabular}

Table 3. Different printing systems with corresponding inverse Ohnesorge number for the YBCO ink.

\begin{tabular}{|c|c|c|c|}
\hline Printing system & $\begin{array}{l}\text { Nozzle diameter } \\
\left(\left(\times 10^{-6} \mathrm{~m}\right)\right.\end{array}$ & $\begin{array}{l}\text { STO } \\
\text { Oh}^{-1}\end{array}$ & $\begin{array}{c}\text { YBCO } \\
\mathrm{Oh}^{-1}\end{array}$ \\
\hline DMP2800 & $\begin{array}{c}9 \\
22 \\
\end{array}$ & 14.4 & $\begin{array}{l}4.04 \\
6.31\end{array}$ \\
\hline Microfab & $\begin{array}{l}30 \\
60\end{array}$ & 16.8 & $\begin{array}{c}7.37 \\
10.42\end{array}$ \\
\hline
\end{tabular}

The droplet formation process for the Microfab piezoelectric printheads ( 30 and $60 \mu \mathrm{m}$ ) can be visualized using a camera system and a strobed LED controlled using an in-house written software. Every image is averaged over several $(>10)$ droplets, this to enhance the reliability of the droplet formation process. Here, satellite droplet formation should be avoided, while a welldefined vertical droplet trajectory is envisaged. The different stages of the droplet formation of an aqueous YBCO ink are visualized in Fig. 3, confirming the coalescence of the ink stream into a single drop within $0.5 \mathrm{~mm}$ of the orifice. Here, one droplet contains $90 \mathrm{pL}$ ink, calculated from the software.

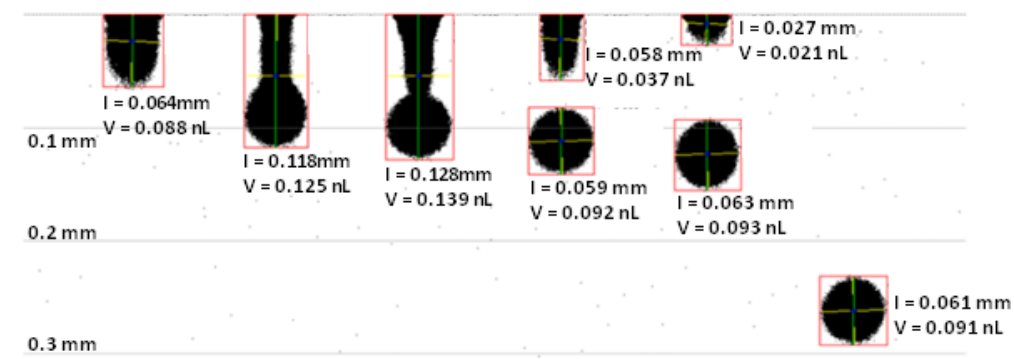

Fig. 3 Drop visualization at specific delay times, with $\mathrm{V}$ the total drop volume and $\mathrm{I}$ the droplet diameter.

After identifying the proper jetting parameters, the wetting behavior of the ink onto the used substrate needs to be characterized and if necessary optimized. This is done by measuring the contact angles of the ink on the substrates. A theoretical footprint of the ejected droplet on the used substrate can then be calculated according to the following formula stipulated by Derby[15]:

$$
\mathrm{d}_{\mathrm{con}}=\mathrm{d}_{0} \sqrt[3]{\frac{8}{\tan \frac{\theta}{2}\left(3+\tan ^{2} \frac{\theta}{2}\right)}}
$$

In which $\mathrm{d}_{\mathrm{con}}, \mathrm{d}_{0}$ and $\theta$ are the droplet diameter after contact onto the substrate, droplet diameter in flight and the equilibrium contact angle. The minimum width $\left(=\mathrm{d}_{\mathrm{con}}\right)$ of a pattern can be predicted with this equation. More data can be found in [5]. Especially in case of patterned printing this information is crucial to estimate the resolution for any print head/ink/substrate combination.
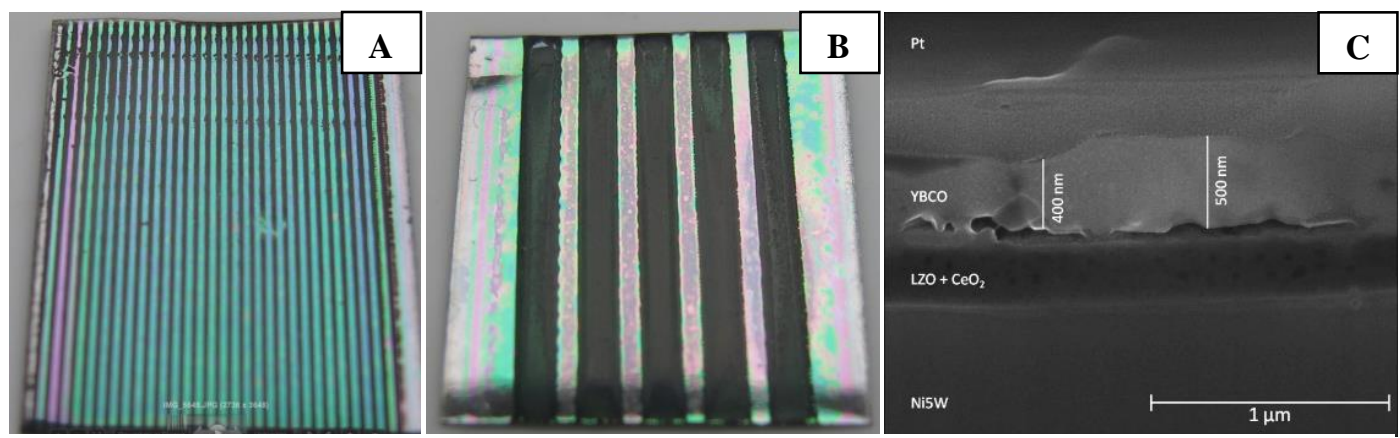

Fig. 4 (a) $200 \mu \mathrm{m}$ wide single and (b) $1 \mathrm{~mm}$ wide composed YBCO patterns on buffered Ni-5at\%W substrates after complete thermal processing. (c) FIB-SEM measurement of a $200 \mu \mathrm{m}$ wide pattern. 
A proof of concept for printing YBCO patterns on buffered Ni-5at\%W substrates is shown in Fig. 4. Here, printing was performed using a Microfab printing system with a $30 \mu \mathrm{m}$ nozzle. Additionally, increasing the number of successive coatings from four to six, a thickness increase was obtained. In Fig. 4, both (a) single and (b) composed YBCO patterns were printed on buffered tape. For the latter, ten, $100 \mu \mathrm{m}$ wide, patterns are overlapping each other with the formation of a $1 \mathrm{~mm}$ wide pattern. Dense YBCO patterns of 400 to $500 \mathrm{~nm}$ thick were obtained, as verified by FIB-SEM analysis (Fig. 4 c).

\section{Nanoparticle containing inks}

Next to solution based inks, nanoparticles inks can be used for the ink-jet printing of ceramic coatings. Here, we distinguish between an ink solely consisting of NPs and an ink containing both complexated metal ions as NPs. These types of inks offer interesting advantages such as lower processing temperatures (solely NPs ink) or enhanced properties of the functional coating (metal ions-NPs ink). Yet, these types of inks are affected by some limitation. Only a few type of NPs are commercially available which leads to the need for in-house development of NP synthesis. Moreover, the stabilization of the NPs, in a certain solvent or metal-based precursor, to generate a suitable ink is not straightforward.

\section{Nanoparticle synthesis}

A variety of methods are available to synthesize nanoparticles, like co-precipitation, sol-gel, reversed-micelle, combustion, hydro-/solvothermal and surfactant-based synthesis.[24-27] However, most of these methods suffer from long reaction times, broad particle size distribution, the generation of amorphous, large and/or agglomerated particles. Some methods can yield unagglomerated, crystalline NPs, yet in general expensive and/or toxic precursors are used. We focus on microwave-assisted solvothermal synthesis, with environmentally friendly solvents, e.g. benzyl alcohol, isopropanol, ethanol and water. Microwaves directly couple with the precursor solution, resulting in an efficient energy transfer which leads to shorter reaction times.[12]

As an example, TEM images of $\mathrm{TiO}_{2}, \mathrm{ZrO}_{2}$ and $\mathrm{HfO}_{2}$ nanoparticles synthesized via microwave methods are shown in Fig. 5. The $\mathrm{TiO}_{2}$ nanoparticles are synthesized by a microwave-assisted hydrothermal treatment at $140^{\circ} \mathrm{C}$ for 20 minutes on a precursor containing titanium(IV) propoxide stabilized in $\mathrm{H}_{2} \mathrm{O}$ by complexation with EDTA, aided by triethanolamine as a base. The $\mathrm{ZrO}_{2}$ and $\mathrm{HfO}_{2}$ nanoparticles are synthesized from zirconium(IV) chloride and hafnium(IV) chloride in benzyl alcohol respectively.[14, 28] The $\mathrm{ZrO}_{2}$ and $\mathrm{HfO}_{2}$ nanoparticles are agglomerated after synthesis, yet a post-modification with a long chain carboxylic acid (oleic acid, dodecanoic acid...) and a base (oleyl amine, trimethyl ammonium hydroxide...) allows the nanoparticles to become agglomeration-free in chloroform.[14]
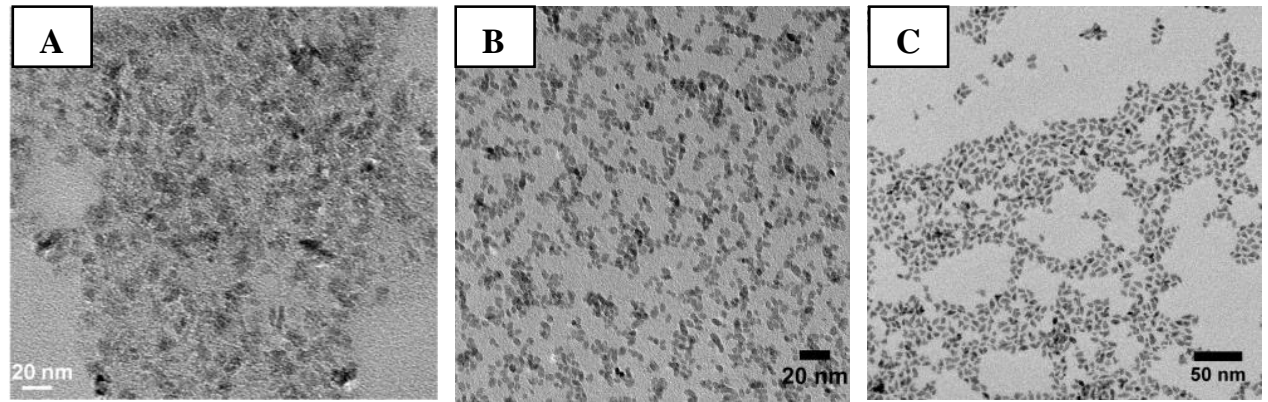

Fig. 5 TEM images of $\mathrm{TiO}_{2}(\mathrm{~A}), \mathrm{ZrO}_{2}(\mathrm{~B})$ and $\mathrm{HfO}_{2}(\mathrm{C})$ nanoparticles. 


\section{Nanoparticle inks}

In order to use NPs in an ink, either solely or in combination with (complexated) metal ions, they should be stable before the ink can be printed. In reality, this means that if any agglomerates are present they should be smaller than the nozzle's orifice to avoid nozzle blockage and when NPs are mixed with a metal ion solution in particular, the NPs should not disturb any metal complexes in the ink which can cause precipitation. The agglomeration-degree of the NPs is analyzed through dynamic light scattering (DLS) measurements. DLS measures the movement of the particles in solution and relates this to the hydrodynamic diameter of the particles. [29] The real NP size is known from TEM, so if high values for the hydrodynamic diameters are obtained in DLS, than we know that the nanoparticles are moving together in solution, meaning they are agglomerated. Off course, the rheology of these ink should also be determined and if necessary adapted, similar as explained above for the inks solely containing metal ions, before the ink is used.

Figure 6 shows a TEM image of $\mathrm{ZrO}_{2} \mathrm{NPs}$ directly stabilized in chloroform after synthesis with a long chain carboxylic acid and a base, as was mentioned above. The TEM image shows small individual, agglomeration-free NPs of 5-10 nm in diameter. DLS analysis of these NPs in chloroform confirms that they are agglomeration-free in solution. The $\mathrm{ZrO}_{2} \mathrm{NPs}$ can also be stabilized in methanol when a smaller carboxylic acid, like nonanoic acid, is used (Fig. 6).
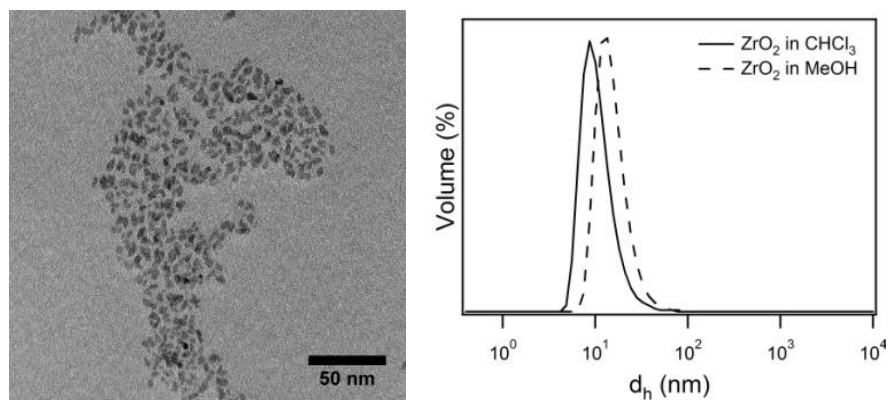

Fig. 6 TEM image of $\mathrm{ZrO}_{2}$ NPs in chloroform and DLS measurements of $\mathrm{ZrO}_{2}$ in chloroform (-) and methanol (- -).

\section{APPLICATIONS}

\section{High temperature $\mathrm{YBa}_{2} \mathrm{Cu}_{3} \mathrm{O}_{7-\mathrm{x}}$ superconductors}

The development of high-temperature superconductors has reached the level of high performance applications such as magnets, generators and transformers. However, $\mathrm{YBa}_{2} \mathrm{Cu}_{3} \mathrm{O}_{7-\mathrm{x}}$ (YBCO) superconductors, as any ceramic metal oxide, are brittle materials and are not easily formed into long flexible so-called coated conductors. As described above, we developed an environmental-friendly, water-based YBCO precursor ink suitable for printing after carefully studying the coordination chemistry together with its specific rheology. We are able to deposit these inks via ink-jet printing and the deposited layers are thermally treated according to a specific program to render a highly oriented YBCO layer.[1] The sintered sample shows a homogeneous coating on a $\mathrm{SrTiO}_{3}$ substrate with the absence of cracks, and XRD analysis confirms the c-axis oriented crystalline YBCO phase (Fig. 7). A current density $\mathrm{J}_{\mathrm{c}}$ of $0.67 \mathrm{MA} / \mathrm{cm}^{2}$ is measured via an inductive measurement using a cryoscan at $77 \mathrm{~K}$ in self-field for a thickness of $350 \mathrm{~nm}$ (Fig. 7). It is also worth mentioning that this technique uses a third harmonic wave to identify the superconductive current. Here, the $50 \mu \mathrm{V}-3 \mathrm{f}$ criterion is used which is comparable to the standard $1 \mu \mathrm{V}$ resistive voltage drop over $1 \mathrm{~cm}$ length.[30]

One of the main shortcomings of YBCO as a superconductor material is the dependence of the $\mathrm{J}_{\mathrm{c}}$ on the magnetic field strength and orientation in high-field applications, like wind mill energy in 
which the superconductor is coated as a coil.[31] It has been shown that these problems can be circumvented by the introduction of various structural and morphological defects in the superconducting layer, so-called artificial pinning centers (APCs).[30] We want to use carefully chosen ceramic NPs as APCs, and by synthesizing these NPs separately, a better control over particle growth, size and shape is possible. This topic is still ongoing research in our lab, and this brings us closer to the incorporation of these superconductors in high and alternating magnetic field applications, like in alternative energy generation.
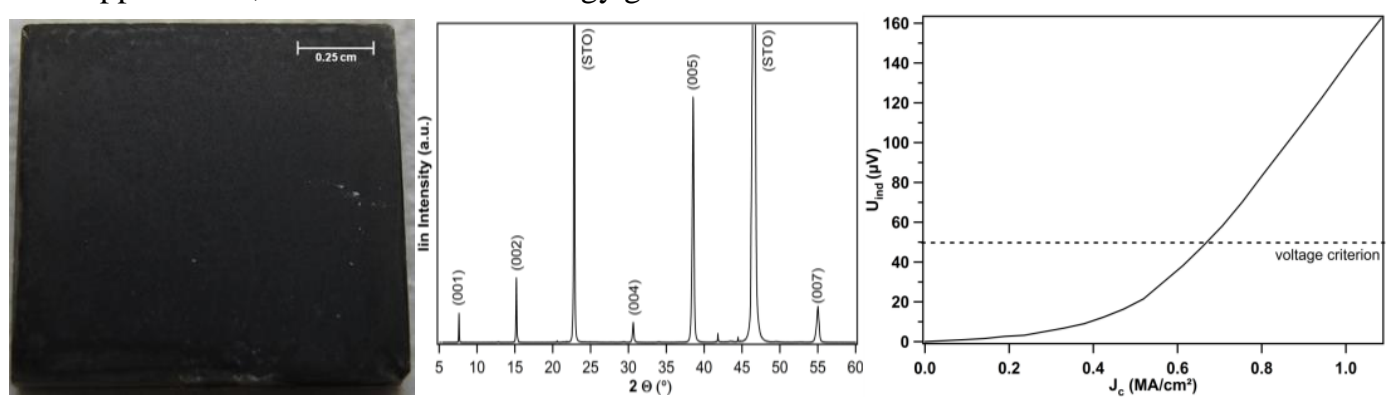

Fig. 7 From left to right homogeneous coating of YBCO on a $\mathrm{SrTiO}_{3}$ substrate after thermal processing, XRD diffractogram of the treated YBCO layer showing strongly oriented crystalline YBCO phase and critical current measurement of the treated YBCO layer (350 $\mathrm{nm}$ thickness) showing a Jc of $0.67 \mathrm{MA} / \mathrm{cm}^{2}$ in self-field.

\section{$\mathrm{TiO}_{2}$ coating}

Self-cleaning coatings on glass are based on the photocatalytic activity of crystalline $\mathrm{TiO}_{2}$. Today, most of these transparent coatings are fabricated from expensive vacuum processing: sputtering or chemical vapor deposition. However, ink-jet printing from $\mathrm{Ti}^{4+}$ solution based inks proves a viable alternative.[16] However, all of these approaches suffer from an important drawback: in order to be photocatalytically active, $\mathrm{TiO}_{2}$ needs to be crystalline, which requires processing temperatures of $400^{\circ} \mathrm{C}$ or higher. So, this means that none of the methods are suited to deposit active coatings on heat sensitive substrates. Here, we used a suspension ink, containing pre-synthesized $\mathrm{TiO}_{2}$ nanocrystals and we illustrate (Fig. 8) that even at temperatures below $250^{\circ} \mathrm{C}$, active self-cleaning layers can be prepared.[18] However, the layer treated at $150^{\circ} \mathrm{C}$ show is badly attached to the substrate, causing a release of the absorbed methylene blue and thus an increase in absorbance after 60 minutes.

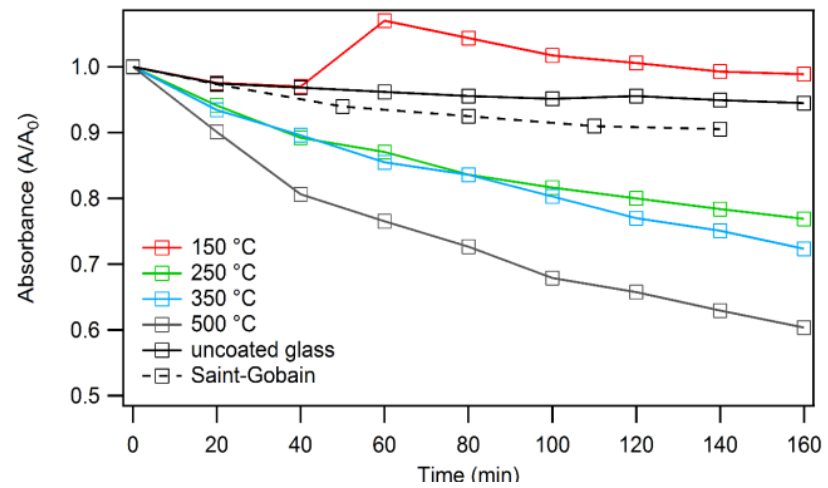

Fig. 8 Photodegradation of a methylene blue solution under $\mathrm{UV}$-illumination upon contact with $\mathrm{TiO}_{2}$ layers on glass obtained from ink jet printing of $\mathrm{TiO}_{2}$ nanoparticles containing inks treated at different calcination temperatures. 


\section{REFERENCES}

1. J. Feys, P. Vermeir, P. Lommens, S. C. Hopkins, X. Granados, B. A. Glowacki, M. Baecker, E. Reich, S. Ricard, B. Holzapfel, P. Van der Voort, I. Van Driessche. J. Mater. Chem. 22, 3717-3726 (2012).

2. G. Penneman, I. Van Driessche, E. Bruneel, S. Hoste. Trans Tech Publications Ltd 264268, 501-504 (2004).

3. G. Pollefeyt, S. Clerick, P. Vermeir, J. Feys, R. Hühne, P. Lommens, I. V. Driessche. Supercond. Sci. Technol. 27, 095007 (2014).

4. G. Pollefeyt, S. Clerick, P. Vermeir, P. Lommens, K. De Buysser, I. Van Driessche. Inorganic Chemistry 53, 4913-4921 (2014).

5. I. Van Driessche, J. Feys, S. C. Hopkins, P. Lommens, X. Granados, B. A. Glowacki, S. Ricart, B. Holzapfel, M. Vilardell, A. Kirchner, M. Backer. Supercond. Sci. Technol. 25, 065017 (2012).

6. I. Van Driessche, G. Penneman, C. De Meyer, I. Stambolova, E. Bruneel, S. Hoste. Trans Tech Publications Ltd 206-2, 479-482 (2002).

7. P. Lommens, J. Feys, H. Vrielinck, K. De Buysser, G. Herman, F. Callens, I. Van Driessche. Dalton Trans. 41, 3574-3582 (2012).

8. M. Baghbanzadeh, L. Carbone, P. D. Cozzoli, C. O. Kappe. Angew. Chem.-Int. Edit. 50, 11312-11359 (2011).

9. I. Bilecka, I. Djerdj, M. Niederberger. Chem. Commun., 886-888 (2008).

10. I. Bilecka, M. Niederberger. Nanoscale 2, 1358-1374 (2010).

11. N. Dahal, S. Garcia, J. P. Zhou, S. M. Humphrey. ACS Nano 6, 9433-9446 (2012).

12. S. Shi, J.-Y. Hwang. Journal of Minerals \& Materials Characterization \& Engineering 2 , 101-110 (2003).

13. E. Solano, L. Perez-Mirabet, F. Martinez-Julian, R. Guzman, J. Arbiol, T. Puig, X. Obradors, R. Yanez, A. Pomar, S. Ricart, J. Ros. J. Nanopart. Res. 14, 1034 (2012).

14. J. De Roo, F. Van den Broeck, K. De Keukeleere, J. C. Martins, I. Van Driessche, Z. Hens. Journal of the American Chemical Society 136, 9650-9657 (2014).

15. B. Derby Annual Reviews 40, 395-414 (2010).

16. M. Arin, P. Lommens, N. Avci, S. C. Hopkins, K. De Buysser, I. M. Arabatzis, I. Fasaki, D. Poelman, I. Van Driessche. Journal of the European Ceramic Society 31, 1067-1074 (2011).

17. M. Arin, P. Lommens, S. C. Hopkins, G. Pollefeyt, J. Van der Eycken, S. Ricart, X. Granados, B. A. Glowacki, I. Van Driessche. Nanotechnology 23, 165603 (2012).

18. M. Arin, J. Watte, G. Pollefeyt, K. De Buysser, I. Van Driessche, P. Lommens. J. Sol-Gel Sci. Technol. 66, 100-111 (2013).

19. A. Kirchner, M. Arin, P. Lommens, X. Granados, S. Ricart, B. Holzapfel, I. Van Driessche. J. Alloy. Compd. 516, 16-19 (2012).

20. I. Van Driessche, S. Hopkins, P. Lommens, X. Granados, D. Andreouli, B. Glowacki, I. M. Arabatzis, M. Arin, S. Ricart, I. Fasaki, E. Georgiopoulos, R. Tomov. Nanosci. Nanotechnol. Lett. 5, 466-474 (2013).

21. K. Vernieuwe, P. Lommens, J. C. Martins, F. Van den Broeck, I. Van Driessche, K. De Buysser. Materials 6, 4082-4095 (2013).

22. L. Alderighi, P. Gans, A. Ienco, D. Peters, A. Sabatini, A. Vacca. Coordination Chemistry Reviews 184, 311-318 (1999).

23. E. Tekin, P. J. Smith, U. S. Schubert. Soft Matter 4, 703-713 (2008).

24. K. De Keukeleere, J. Feys, M. Meire, J. De Roo, K. De Buysser, P. Lommens, I. Van Driessche. J. Nanopart. Res. 15, 2074 (2013).

25. M. Niederberger, G. Garnweitner. Chem.-Eur. J. 12, $7282-7302$ (2006).

26. J. Park, J. Joo, S. G. Kwon, Y. Jang, T. Hyeon. Angew. Chem.-Int. Edit. 46, 4630-4660 
(2007).

27. M. Veith, S. Mathur, N. Lecerf, V. Huch, T. Decker, H. P. Beck, W. Eiser, R. Haberkorn. J. Sol-Gel Sci. Technol. 17, 145-158 (2000).

28. J. De Roo, K. De Keukeleere, J. Feys, P. Lommens, Z. Hens, I. Van Driessche. J. Nanopart. Res. 15, 1778 (2013).

29. Malvern Technical note: DLS - an introduction in 30 minutes.

30. J. Kunert, M. Bäcker, O. Brunkahl, D. Wesolowski, C. Edney, P. Clem, N. Thomas, A. Liersch Supercond. Sci. and Technol. 24, 085018 (2011).

31. X. Obradors, T. Puig, A. Palau, A. Pomar, F. Sandiumenge, P. Mele, K. Matsumoto. Academic Press 303-349 (2011). 